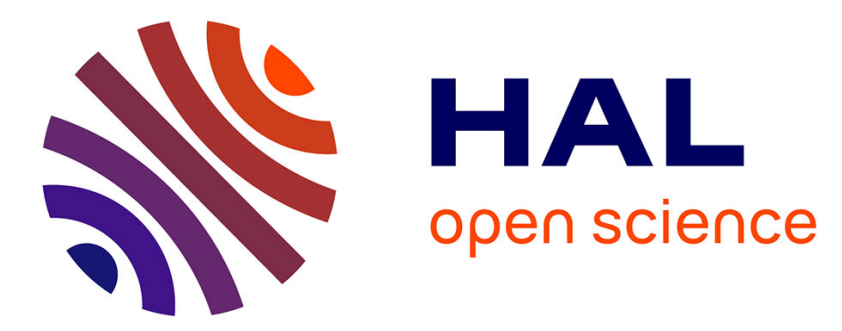

\title{
Rosy apple abundance is shaped by vegetative growth and water status
}

Aurélie Rousselin, Danièle Bevacqua, Gilles Vercambre, Marie-Hélène Sauge, Francoise Lescourret, Marie Odile Jordan

\section{- To cite this version:}

Aurélie Rousselin, Danièle Bevacqua, Gilles Vercambre, Marie-Hélène Sauge, Francoise Lescourret, et al. Rosy apple abundance is shaped by vegetative growth and water status. Crop Protection, 2018, 105, pp.1-9. 10.1016/j.cropro.2017.11.001 . hal-02621135

\section{HAL Id: hal-02621135 \\ https://hal.inrae.fr/hal-02621135}

Submitted on 26 May 2020

HAL is a multi-disciplinary open access archive for the deposit and dissemination of scientific research documents, whether they are published or not. The documents may come from teaching and research institutions in France or abroad, or from public or private research centers.
L'archive ouverte pluridisciplinaire HAL, est destinée au dépôt et à la diffusion de documents scientifiques de niveau recherche, publiés ou non, émanant des établissements d'enseignement et de recherche français ou étrangers, des laboratoires publics ou privés.

\section{(1) (1) $\$$}

Distributed under a Creative Commons Attribution - NonCommercial - NoDerivatives| 4.0 
3 Aurélie Rousselina, Daniele Bevacqua ${ }^{a}$, Gilles Vercambrea, Marie-Hélène Sauge ${ }^{a}$, Françoise Lescourret ${ }^{a}$,

\section{Marie-Odile Jordan $^{\mathrm{a}^{*}}$}

6 a: INRA, UR1115 Plantes et Systèmes de culture Horticoles (PSH), Domaine Saint-Paul, Site Agroparc, 84914

7 Avignon cedex 09, France

8 *: corresponding author. Marie-Odile.Jordan@avignon.fr

10 Key message: Rosy apple aphid abundance is positively correlated to plant vegetative growth at both the shoot and

11 tree scales. Water restriction has a negative impact on aphid abundance only at the tree scale.

\section{Highlights}

Rosy apple aphid abundance on apple is related to growth at both the shoot and the tree scale

This relation is modulated by genotype and water supply

At the shoot level the effect of water restriction on aphid abundance depends on genotype At the tree level, water restriction always has a negative impact on aphid abundance

\section{Abstract}

20 Regulated deficit irrigation, which is a common practice to cope with water scarcity, can impact plant-aphid

21 interactions, and possibly lead to a reduction in the use of pesticides. To test the possible effect of water restriction

22 on the apple tree-rosy apple aphid (Malus domestica-Dysaphis plantaginea) system, we performed a factorial

23 experiment with two levels of water supply and two genotypes on artificially infested trees. Plant growth and aphid

24 abundance were characterized during the entire infestation period at two scales of analysis: the apical shoot scale

25 and the tree scale, and additional measures were performed to evaluate plant water status. Aphid abundance

26 increased with plant vegetative growth at both scales of analysis, which is consistent with the Plant Vigor

27 Hypothesis (i.e. with the fact that most of the phloem feeders prefer fast growing plants). At the tree scale, aphid

28 abundance was lower on trees that underwent water restriction, but at the shoot scale, aphid abundance responded

29 differently to water restriction depending on the tree genotype. Water restriction modified the relationship between

30 aphid abundance and growth, thus indicating that host suitability for aphids was affected by different plant 
variables susceptible to water stress, among which growth. The different response patterns at the two scales of analysis highlight the importance of scale choice in the study of plant-insect interactions.

Keywords: Dysaphis plantaginea, Malus domestica, pest management, drought stress, Plant Vigor Hypothesis

\section{INTRODUCTION}

Reducing the use of pesticides and coping with water scarcity are two of the main challenges in

Mediterranean horticulture. The use of less drought susceptible plant varieties and the implementation of regulated deficit irrigation represent possible solutions to decrease water consumption in horticulture. Interestingly, due to cross tolerance mechanisms between abiotic and biotic stresses, the implementation of deficit irrigation can also reduce host plant suitability for pests and especially aphids (Foyer et al., 2016). Host plant suitability for aphids encompasses multi-aspects, which can be modulated by plant water status. The four main ones are (i) nutrition (or settlement) site availability, i.e. the number of growing apices (Forrest and Dixon, 1975), (ii) phloem nutritional quality, e.g. the secondary metabolites (Czerniewicz et al., 2011) and the amino acid profiles (Ryan et al., 2014), (iii) phloem accessibility (Mody et al., 2009) and (iv) phyllosphere microenvironment (Pangga et al., 2012). As the effects of water scarcity on host plant characteristics vary with stress timing, intensity, and duration (Tariq et al., 2012), the published results on the effect of host plant water stress on aphid performance, are often contradictory. Water stress has been shown to have a positive (Archer et al., 1995; Mewis et al., 2012), a negative (Agele et al., 2006; King et al., 2006; Simpson et al., 2012) or no effect (Bethke et al., 1998; King et al., 2006; Mewis et al., 2012) on aphid performance. The plant genotype is also a factor that is expected to influence the plant-aphid interaction under water restriction. Yet, the studies evaluating the effects of drought stress on aphid performance on different plant genotypes generally considered genotypes contrasted for their resistance to the insect (Agele et al., 2006; Dardeau et al., 2015; Verdugo et al., 2015) rather than genotypes contrasted for their response to drought stress.

In the present work, the apple tree-rosy apple aphid system [Malus domestica Borkh. - Dysaphis plantaginea (Passerini)] was chosen as the study case, because apple trees are cultivated worldwide under a wide range of climatic conditions and also in semi-arid areas such as the Mediterranean basin. Moreover apple is the major deciduous fruit tree production worldwide (FAO 2016). Dysaphis plantaginea is a major apple tree pest (Forrest and Dixon, 1975). It causes leaf roll (Forrest and Dixon, 1975), shoot and fruit deformations (Marchetti et al., 2009), and populations resistant to pesticides have already appeared (Delorme et al., 1999). Two apple 
61 genotypes with different drought response mechanisms were identified from a “Starkimson”×"Granny Smith”

62 cross progeny (Lauri et al., 2016). The first genotype (referred to as DAG: Drought Avoidance Genotype) is

63 characterised by drought avoidance strategy, with reduced stomatal conductance and photosynthesis under water

64 deficit, growth being affected to a smaller extent. The second one (referred to as GCG: Growth Cessation

65 Genotype) is characterised by a high percentage of shoots experiencing growth cessation under drought stress. We

66 intend to use these contrasted genotypes to test how far the mechanism involved in drought resistance affects the

67 apple tree - rosy apple aphid interactions, namely under water stress conditions whose effects on shoot growth may

68 be modulated by the genotype. Other determinants of plant suitability to aphids, such as leaf water potential and

69 gas exchange rates, may also be affected to a greater of lesser extent according to genotype. The related 70 physiological traits, namely leaf temperature (Satar et al., 2008), turgor pressure (Verdugo et al., 2015), phloem sap

71 soluble sugars content (Zehnder and Hunter, 2009) and viscosity (Sevanto, 2014) to which aphids are sensitive,

72 could by modified in turn. The relationship between shoot growth and aphid performances may therefore be

73 disentangled by water stress conditions.

Thus, aphid abundance has been positively correlated to vegetative growth at the shoot scale (Stoeckli et al., 2008; Rousselin et al., 2016). Yet, the existence of a similar relationship at the tree scale remains unclear. Indeed, the susceptibility of tree organs to aphids may vary within the tree, between long and short shoots and between fruiting and non-fruiting shoots (Simon et al., 2011). This could affect the patterns of aphid dispersion within the crown. We will therefore consider simultaneously two study scales: the infested shoot and the whole tree, thus verifying if the relation between aphid abundance and growth still holds at the tree scale, and how far it is affected by water stress conditions.

To reach these goals, both apple genotypes were submitted to contrasted irrigation regimes, i.e. control vs

82 deficit irrigation, and the aphid population monitored after artificial infestation as well as tree growth, leaf gas

83 exchanges and leaf water potential. Gathered data were then analysed via hierarchical analysis of multiple

84 regression to test how far the plant genotype and the irrigation treatment affected aphid density, possibly via an

85 effect on the plant vegetative growth.

\section{$86 \quad z$ MATERIAL AND METHODS}

\section{2.1. Experimental design and plants}

88 The experiment was conducted in Avignon (southern France) under an $126 \mathrm{~m}^{2}$ insect proof shelter (PEHD Cristal

$89500 * 600 \mu \mathrm{m}$ mesh), insulated from the ground with a tarpaulin (PP 86gr UV stabilized), and treated with various

90 chemicals to eliminate weeds, insects, culture auxiliaries and pests. This treatment was applied first on bare soil 
91 when the tunnel was built (2013) then repeated without herbicide every year (in February). The trees were

92 therefore moved for two weeks to a nearby clean shelter which also allowed control of the tarpaulin status and

93 manual weeding of the few plants that would have grown through. From 10/April/2015 until the end of the

94 experiment (1/July/2015), the temperature under the shelter was recorded every 30 min using a Hobo® Pro V2

95 logger (U23-002, Onset ${ }^{\circledR}$, Bourne, USA).

For each of the two apple genotypes DAG and GCG (described in introduction), 30 scions were whip

97 grafted on M9 Pajam 2 on March 2014. They were grown in 12 L-pots filled with a medium consisting of 1:2 (v:v)

98 perlite and potting soil (Florabella ${ }^{\circledR}$ Klasmann-Deilmann ${ }^{\circledR}$ ). Two drippers per pot, each with a delivery rate of 2

$99 \mathrm{dm}^{3} \mathrm{~h}^{-1}$ and connected to a different pipe, provided respectively tap water and an NPK fertilizer. left with 15 non latent buds (i.e. meaning that the trunk was pruned back to less than $80 \mathrm{~cm}$ above the grafting point). Pruning wounds were protected with Phytopast ${ }^{\circledR}-\mathrm{G}$. The differentiation of the irrigation treatments started on 24/Apr/2015. The pots were covered with a white plastic sheet to avoid penetration of rain water. Two sets of 12 plants of each genotype were selected for their homogeneity, and subjected to two different watering treatments, denoted by $\mathrm{W}+$ and $\mathrm{W}-$. Plants assigned to the $\mathrm{W}+$ treatment were daily irrigated until run-off and the plants assigned to the $\mathrm{W}$ - treatment received a halved water supply. The $\mathrm{W}$ - treatment was adjusted by reducing the duration of each of the two to four daily irrigation periods.

\subsection{Aphid rearing and infestation}

110 To ensure that individual aphids did not genetically differ in their intrinsic performance, a single clone of $D$.

111 plantaginea (Dp15) was used for the infestation. The aphid colony was established from a single female collected

112 on an apple tree 'Ariane' on 26/March/2015 in Avignon. Aphids were reared in the laboratory on the apple cultivar

113 M9 susceptible to aphids, under parthenogenesis-inducing conditions: $20^{\circ} \mathrm{C}+/-1^{\circ} \mathrm{C}, 60-70 \%$ relative humidity and

114 a 16-h-day cycle (Sauge et al., 1998). Five 7-days old wingless adult females were placed on one single current

115 year axis (i.e. which had emerged on the trunk in early spring) per plant on 28/April/2015. The chosen axis for

116 infestation was positioned in the apical position of the trunk. Aphids were then free to disperse all over the plant

117 but could not move to the soil, being blocked by a glue barrier (Rampastop ${ }^{\circledR}$, Protecta ${ }^{\circledR}$ ) provided at the stem

118 base, neither to a neighbouring plant since spacing was large enough to avoid canopy contact throughout the 119 experiment. 


\subsection{Data collection}

122 The infested trees were monitored weekly from the 30/April/2015 to the 01/July/2015 for vegetative growth and

123 from the 04/May/2015 to the 01/July/2015 for aphid abundance. Vegetative growth was computed by counting the

124 number of expanded leaves separately on each developing proleptic bud, or bud formed in 2014 whose

125 development was delayed by dormancy (Wheat, 1980). Two types of vegetative proleptic structures were

126 distinguished: (i) rosettes, which correspond to the expansion of the preformed leaves of the bud, and (ii) shoots,

127 which correspond to a main axis resulting from the activation of the apical meristem (i.e. to the transformation of

128 the rosettes into axes) and all its axillary structures. The diameter at the trunk base, considered as an accurate

129 indicator of plant vigor and classically used as a covariable to explain interplant variability (Nesme et al., 2005),

130 was measured at the start and at the end of the experiment. It varied by less than $12 \%$ within the tree populations

131 sorted by genotype (April 4) and treatment combination (July 2). This variability was too small to affect the

132 number of leaves or the aphid abundances, as shown by preliminary covariance analyses (data not shown)

133 performed at shoot and tree scale. Aphid abundance was estimated by assigning to each proleptic structure (shoot

134 or rosette) one class of infestation: C0 (no aphid), C1 (1 to 5 individuals), C2 (6 to 25), C3 (26 to 125), C4 (125 to

135 625) and C5 (more than 625) (Grechi et al., 2008, Rousselin et al., 2016). As a result, a total of 629 proleptic

136 structures (an average of 13 per tree) were monitored, among which 55\% were assigned to class C4 or C5 at the

137 time of infestation peak.

During the same period, midday leaf water potentials were measured with a Scholander pressure bomb on

139 eight sunny dates (i.e. approximately once a week according to the weather conditions) on a subsample of 3 to 6

140 randomly chosen trees per treatment, using a non-infested sun-exposed leaf near an apex. Simultaneously, leaf

141 photosynthetic rate, leaf stomatal conductance, leaf transpiration and leaf temperature were measured on a non-

142 infested sun-exposed attached leaf with an open gasometric system LCA-4 (ADC®, Hoddesdon, UK).

143

\subsection{Data analysis}

Hereafter, dates are expressed in days after infestation (DAI). Doing so, 28/April/2015 corresponds to 0

146 DAI and 01/July/2015 corresponds to 64 DAI. Possible differences in leaf water potential, leaf photosynthetic rate,

147 leaf transpiration rate, leaf stomatal conductance, leaf temperature, the percentage of tree leaves on a shoot,

148 numbers of developing buds, shoots and rosettes, were analysed with Kruskal-Wallis tests on treatment groups

149 (water $\times$ genotype) and, when significant, they were followed by non-parametric Tukey multiple comparisons. 
151 the apical shoot) and the tree scale. The vegetative growth was computed as the increase in the number of fully

152 expanded leaves between two and 64 DAI, at the shoot scale considering the apical infested proleptic axis plus all

153 its axillary structures, leading to the final shoot vegetative growth (FSVG) and at the tree scale, considering all

154 types of proleptic structures, i.e. rosettes and shoots, leading to final tree vegetative growth (FTVG). Both vegetative growth variables (i.e. FSVG and FTGV) were log transformed to fulfil the conditions required for statistical analysis.

The actual aphid abundance, was estimated from the reported infestation classes by drawing a value from a uniform distribution with boundaries relevant to the different abundance classes (e.g. 125 - 624 for the infestation level C4), for each of the 629 proleptic structures (shoots and rosettes) and sampling dates. It is therefore evident that any reconstruction of the actual aphid abundance differed from another due to the randomness of the drawing process. We constructed 10,000 virtual aphid abundance curves per shoot and then per tree (by summing the values

162 obtained for the proleptic structures belonging to each individual tree). At tree scale, the rosettes contributed to less than $20 \%$ to aphid abundances, despite the fact that they represented $36 \%$ of the proleptic structures whatever the genotype or the irrigation treatment (see Results section). Indeed, the aphid abundances were significantly lower on the rosettes than on the shoots for all measurements dates (Kurskall-Wallis tests, $\mathrm{p}<0.001$ for all tests, undetailed data). The aphid indexes, representative of the infestation severity throughout the infestation period, were calculated as the sums of the actual aphid abundances estimated for each notation date at infested shoot and tree scales. This synthetic variable was representative of the diversity of the infestation dynamics among the proleptic structures (and among the trees) taking into account the infestation duration and the evolution of the aphid population while present on the shoots. The median values (over the 10,000 random resamples) obtained at the tree

171 level or at the infested shoot level were then used for statistical analysis. Such a resampling procedure is intended

172 to obtain continuous variables (e.g. aphid abundance and aphid index), rather than a categorical one (e.g. reported

173 classes of infestation) to describe a continuous value: the aphid abundance. Using a continuous variable simplified

174 moreover the scale change, allowing the calculation of the tree aphid abundance from the data collected on its constitutive proleptic structures. 
Information Criterion). One model was assumed to be better than another if $\triangle$ AICc > 2 (Bolker, 2008), consequently the models with a value of $\triangle \mathrm{AICc}$ of more than 2 from the best models were ignored. After being run

182 on the median values of aphid indexes, the model selection procedure was also run on the 10,000 datasets issued from the transformation of aphid abundance classes into aphid index in order to estimate possible model selection sensitivity to drawings.

To better understand why the effects of irrigation on aphids varied with the study scale (see Results section), we also analysed possible correlations between apical shoot and total tree growth. Therefore, a hierarchical analysis of multiple regression models was performed with final tree vegetative growth (FTVG) as the dependent variable and final shoot vegetative growth (FSVG) as continuous predictor variable and water treatment $\mathrm{W}$ and genotype $\mathrm{V}$ as categorical predictor variables. We then performed the same kind of analyses with FSVG or

190 FTVG as the response variable, and the number of proleptic shoots as the continuous predictor variable and W and

$191 \mathrm{~V}$ as categorical predictor variables. To test if the percentage of tree leaves inserted on shoots was dependant on

192 FTVG, we performed a hierarchical analysis of multiple regression models, with FTVG as continuous variable and $\mathrm{W}$ and $\mathrm{V}$ as categorical variables. packages ‘nparcomp’ and 'glmulti’.

\subsection{Plant water status and leaf functioning}

Trees subject to water restriction, i.e. the $\mathrm{W}$ - trees, had a higher leaf water potential in absolute values than $\mathrm{W}+$ trees (Fig. 1), the differences being significant for DAG (Drought Avoidance Genotype), at 14 (Fig. 1c) and 30 DAI (Days After Infestation, Fig. 1d) and for GCG (Growth Cessation Genotype) at 30 and 58 DAI (Fig. 1h).

Among the same watering treatment there was no significant difference between genotype for leaf water potential, except for 14 and 37 DAI (Fig. 1e) between W+ trees, where GCG W+ had a higher leaf water potential in absolute values than DAG $\mathrm{W}+$.

Over the six monitoring dates of leaf stomatal conductance, leaf photosynthetic rate, leaf transpiration rate and leaf temperature, the differences were significant between the treatments for only one date. On 30 DAI (Fig. 2), leaf stomatal conductance (Fig. 2a) and leaf transpiration rate (Fig. 2b) were reduced for the W- trees compared to the $\mathrm{W}+$ trees for both genotypes. For DAG, leaf photosynthetic rate (Fig. 2c) was significantly higher for W+ trees than W- trees. For GCG, leaf temperature (Fig. 2d) was significantly lower for W+ than W-. 
211 The temporal dynamics of vegetative growth followed similar patterns at the tree and the infested shoot scales with

212 a slowdown of growth after $30 \mathrm{DAI}$ (Fig. 3). The ranking of the different treatments were identical between the two

213 scales with, in decreasing order: the higher vegetative growth for GCG W+, followed by GCG W-, then DAG W+

214 and the smaller vegetative growth for DAG W-. Water restriction decreased vegetative growth for both genotypes.

217 during the infestation period was positively correlated to final shoot vegetative growth FSVG, and the relationship

218 was influenced by both water treatment and tree genotype (Fig 4a). Additionally, FTVG was positively correlated

219 to the number of proleptic shoots per tree (Fig 4b), whereas FSVG was independent of this number (Fig 4c), which

220 was probably a consequence of tree acrotony, as the infested shoot was in the apical position. At shoot and tree

221 scales the ranking of the treatments were consistent. GCG was more vigorous than DAG.

Although the number of proleptic structures per tree was significantly higher for GCG W- than DAG W-,

223 the number of rosettes per tree and the number of shoots per tree did not differ significantly between treatments

224 (data not shown). The percentage of tree leaves inserted on shoots was positively correlated to FTVG since the

225 proportion of tree leaves on shoots increased during the season. Indeed, axes expanded leaves throughout the

226 infestation period while rosettes stopped growing after expansion of their preformed leaves. The percentage of tree

227 leaves inserted on shoots vs rosettes was lower for the trees which underwent a water restriction after 24 DAI,

228 suggesting that $\mathrm{W}+$ shoots grew more vigorously than $\mathrm{W}$ - shoots.

\subsection{Aphid population dynamics}

232 There was at first a period of slow increase of aphid abundance between 0 and 13 DAI, then the aphid population

233 peaked between 29 and 36 DAI and after that there was a quick decrease in aphid abundance at both study scales

234 (Fig. 5). The aphid population started to decrease when the maximal daily temperatures exceeded $42.5^{\circ} \mathrm{C}$. The

235 ranking of the mean aphid abundances of the different treatments at the peak was different between the two scales.

236 However, given the size of the standard deviation these rankings were only indicative of trends. At the infested

237 shoot scale (Fig. 5a), GCG W+ experienced the highest infestation, followed by both genotypes under W- and the 238 lowest infestation was on DAG W+ whereas at the tree scale (Fig. 5b), GCG W+ still experienced the higher

239 infestation but it was followed by DAG W+ and then both genotypes under W- treatment. 
241 3.4. Aphid abundance as related to water supply, genotype and vegetative growth

243 The best model to explain shoot aphid index included the final shoot vegetative growth FSVG, water treatment W,

244 tree genotype $\mathrm{V}$ and the interaction term $(\mathrm{W} \times \mathrm{V})$ (Fig. 6). When considering the 10,000 different estimated aphid

245 index curves, the same model gave the best results in $82.8 \%$ of the cases. At equivalent shoot growth, DAG

246 sustained a more abundant aphid population than GCG. The two genotypes responded oppositely to the water

247 treatment. Thus a water restriction enhanced the positive effect of shoot growth on the aphid index for DAG, but

248 depleted it for GCG.

\subsubsection{At tree scale}

250 The best model to explain the tree aphid index included final tree vegetative growth FTVG, water treatment W and 251 the interaction term FTVG $\times W$ (Fig. 7). This model was selected as the best for $68.5 \%$ of the 10,000 datasets

252 resulting from the transformation of aphid infestation classes into aphid numbers. The second best model took into

253 account FTVG, V, W and the interaction term FTVG $\times$ W had a $\triangle$ AICc of 0.28 and it was selected as the best in

$25431.4 \%$ of the 10,000 runs. Then, an effect of the tree genotype (V) on the tree aphid index cannot be ruled out. At

255 the tree scale, aphid abundance was positively correlated to vegetative growth. The slope of the regression line was

256 smaller for $\mathrm{W}$ - trees compared to $\mathrm{W}+$ trees.

258 Our results showed a positive relationship between vegetative growth and aphid abundance whatever the study scale, the genotype or the water supply. At the shoot scale, tree genotype played a role on aphid abundance in interaction with water supply. Thus, the effects of water restriction on the two genotypes were opposite: it increased aphid abundance on DAG and reduced it on GCG. At the tree scale, aphid abundance was penalized by water restriction and the effect of genotype on aphid abundance was less clear.

The positive relationship between $D$. plantaginea abundance and both shoot and tree vegetative growths is consistent with the Plant Vigour Hypothesis that predicts a better performance of phytophagous insects on vigorous plants or organs (Price 1991). Our result, at the shoot scale, is consistent with another study conducted on apple tree, evidencing that Aphis pomi abundance on a current-year shoot was well correlated to the shoot growth but was independent of trunk diameter and median shoot length that are indicators of tree vigour (Stoeckli et al. 2008).

268 Final tree vegetative growth (FTVG) was positively correlated to the percentage of tree leaves inserted on shoot and also to the number of shoots. However, there was no relation between final apical shoot vegetative growth (or 
FSVG) and the number of shoots per tree, suggesting that, due to their apical position and apple tree acrotony, the

271 infested shoots had priority for vegetative growth with respect to the other shoots. As aphids have been shown to be

272 more performant on long shoots (Grechi et al., 2008; Simon et al., 2011), the most suitable one for aphid

273 development within the tree crown, was likely the apical shoot which grew at the most rapid rate. Apical shoot

274 growth, like tree growth, varied moreover with genotype. Thus, since grafting, GCG was more vigorous than DAG,

275 which could be related either to difference in genotypic vigour or in grafting compatibility. After grafting and

276 throughout 2014, vegetative growth was more important for GCG than for DAG (data not shown). The dry mass

277 suppressed by winter pruning prior to the experiment was consequently significantly higher for GCG (Kruskal-

278 Wallis test, $\mathrm{p}<0.001$, i.e. $41.3 \pm 16.5 \mathrm{~g}$ (mean \pm SD) for GCG vs $25.2 \pm 9.5 \mathrm{~g}$ for DAG). It means that in 2014,

279 GCG had not only more functional leaves but, according to the functional equilibrium theory (Brouwer, 1983), also

280 more roots than DAG, and therefore probably higher amounts of $\mathrm{C}$ and $\mathrm{N}$ stored therein (higher reservoir size and

281 higher C and N intake in 2014). Higher vegetative growth of GCG during the first growth flush of 2015, which

282 correspond to the period of aphid population development, could thus result from higher spring remobilisation

283 (Jordan et al., 2009) or higher pruning intensity (Bevacqua et al., 2012). The infestation dynamic at tree level

284 depended not only on the population increase on a single shoot, but also on aphid dispersion within the crown, which was affected by other aspects of plant development and architecture than solely individual shoot growth. Indeed, dispersion could first depend on tree architecture complexity. On apple- $D$. plantaginea system strong and complex branching decreased infestation, as pedestrian aphids attempting to colonize other plant shoots are less likely to find suitable feeding sites (Simon et al., 2011). However as the architecture of our small trees was quite homogeneous in term of branching complexity, this was unlikely to have played a major role in our study. Dispersion within the tree might also depend on the number of individuals able to feed on the apical shoot, i.e. on

291 the aphid density in relation with phloem sap quality and accessibility, but also on the attractiveness of the other tree shoots compared to apical favoured one. Indeed, aphids preferentially settled on plant stratum with the highest nitrogen availability (Chau et al., 2005) but nitrogen allocation and leaf transpiration (phloem sap flow) vary

294 greatly within a tree as a function of tree height (Livingston et al., 1998), leaf age (Constable and Rawson, 1980), genotype in interaction with leaf area (Tausend et al., 2000), shoot orientation (Le Roux et al., 2012) or cultural practices (Jordan et al., 2011). Therefore, if the phloem quality is poor on a given shoot, aphids are more likely to start roaming about to test other available feeding sites (Nowak and Komor, 2010), or might even return to the apical shoot. The within tree variability varies moreover with stress intensity (Jordan et al., 2012; Ballester et al., 
2013), which might partly explain why deficit irrigation could be oppositely related to aphid abundance at shoot and tree scale.

The effect of water restriction on aphid abundance was partially mediated by vegetative growth, which was reduced by deficit irrigation at shoot and tree scales for both genotypes. However a water restriction also modified the relationship between aphid and vegetative growth, which indicated additional physiological consequences of water restriction on tree suitability for aphid. However, we did not find clear difference among treatments in midday leaf water potential which is correlated to predawn leaf water potential considered as the most accurate indicator of plant water stress (Paço et al., 2013). We therefore hypothesize that water restriction modified several variables related to plant water status, which possibly impact aphid performance. Water restriction could increase sap viscosity (Sevanto, 2014), due to higher solute concentration, which may impair efficient sap uptake by the aphid. Aphids are also affected by phloem carbohydrate concentrations that determine excretion costs (Zehnder and

310 Hunter, 2009), by turgor pressure (Mody et al., 2009; Verdugo et al., 2015) and cell wall thickness (Goggin, 2007;

311 Foyer et al., 2016) that influence phloem accessibility. If the host plant condition is worsened by water restriction

312 (or any other treatment), the aphids modify their feeding behaviour, spending less time in passive ingestion of

313 phloem sap (Lu et al., 2016). They are therefore smaller in size and exhibit longer pre-adult life stage and reduced

314 fecundity (Lu et al., 2016). Intermittent stress seems to impose harsher conditions than a continuous and lasting 315 drought, thus reducing the aphid performances, among which the fecundity, to a greater extent as a continuous drought (Banfield-Zanin and Leather, 2015, on the Stika spruce - green spruce aphid system). Under pulsed stress

317 conditions, tree mortality was also higher when previously infested by aphids (Banfield-Zanin and Leather, 2014), which is consistent with the fact that aphids have been shown to affect their host plant water potential, in ways

319 similar to drought (Cabrera et al., 1995). Notice that in our study the W+ trees were also the most infested, so the 320 differences in the severity of aphid infestation between $\mathrm{W}+$ and $\mathrm{W}$ - might have reduced the difference in leaf water 321 potential observed between the two water treatments.

323 an increased leaf temperature consecutive to a decrease in leaf transpiration after stomata closure as evidenced by

324 Ballester et al. (2013). On 30 DAI, for instance, leaf temperature was significantly higher for GCG W- compared to

325 GCG W+, and the difference was $3.7^{\circ} \mathrm{C}$. These differences could partially explain the more rapid decrease of aphid 326 abundance on the water restricted trees, all the more because the temperatures peaked above $42.5^{\circ} \mathrm{C}$ and up to $32743.3^{\circ} \mathrm{C}$, which is below the lethal temperature for most aphid species (Satar et al. 2008, Hullé et al. 2010). 
At the shoot scale, the effect of water restriction on the relation between vegetative growth and aphid abundance was negative for GCG but positive for DAG. A modulation of genotypic resistance to aphids by water restriction has also been observed on other tree-aphid systems. On both poplar-Phloeomyzus passerinii (Dardeau et al., 2015) and peach tree-Myzus persicae (Verdugo et al., 2015) systems, water stress had no effect on the aphid population on aphid susceptible cultivar, but it increased aphid performance on aphid resistant cultivar. In the present study, deficit irrigation favoured aphid development on the DAG W- apical shoots, despite it also reduced their vegetative growth. We hypothesized therefore that the irrigation treatment modified also other determinants of plant suitability for aphids, among which shoot $\mathrm{N}$ concentration, thereby counterbalancing the expected negative effect of low shoot growth. Indeed, DAG W- had the lowest number of proleptic structures, the difference being significant between DAG W- and GCG W-, so the nitrogen resource (mainly amino acids) might have been less diluted in those trees. Decreased C:N ratio or increased amino acids contents have been shown to increase aphid performance (Nowak and Komor, 2010; Ryalls et al., 2014). This hypothesis relies furthermore on the assumption that the tree aphids gathered on the apical shoot because of its higher nutritional quality due to its position, as shown on the Chrysanthemum-Melon aphid system [Dendranthema grandiflora - Aphis gossypii] in which within plant aphid distribution is driven by nutrient availability (Chau et al., 2005).

The absence of the expected marked differences in physiological measures of the trees of the two genotypes impairs the identification of mechanisms acting differently on aphid performance between the two genotypes. According to Lauri et al. (2016), we expected DAG to close its stomata quicker than GCG. Our measured values of stomatal conductance of well-watered trees are halved compared to the values obtained by Lauri et al. (2016), which may result from the use of a different rootstock, which influenced the response of the plant to water restriction (Liu et al., 2012). Photosynthetic rate was significantly affected by watering treatment for only one date and furthermore only for DAG. In addition, we expected GCG vegetative growth to be more affected by water restriction than DAG, but we obtained the reverse.

The different effects of water restriction on the aphid performance on DAG at tree and shoot levels underlined

352 the importance of the scale choice. Most studies on tree-aphid interaction focused on a few number of sub-sample shoots (Stoeckli et al., 2008; Rousselin et al., 2016), or even at a smaller scale, such as the individual leaf (Mace and Mills, 2015). In the present study we demonstrated that the responses to abiotic constraints might be different at apical shoot and tree scales. As far as orchard aphid management is concerned, the patterns at the tree scale seem more representative of the overall aphid induced damages. Thus the reduction of tree vigour can be a lever to control $D$. plantaginea populations. In addition, trees submitted to water restriction were less favourable to aphids 
than well-watered trees, so it may be possible to address at the same time the water scarcity and the chemical use reduction issues, by reducing water supply in apple orchards. Water restriction has to be applied preferably in spring, i.e. when aphid populations were susceptible to develop on the trees. But, host plant suitability to aphids could probably also be affected by regulated deficit irrigation techniques, currently applied for longer periods but mainly in summer and autumn, techniques which were, to our knowledge, evaluated only for fruit production (Girona et al., 2010). Indeed, a water restriction modifies determinants of plant suitability others than growth, and those effects could last several months, especially when shoot composition is concerned.

Acknowledgements: This work was funded by the ARIMNET (ANR-12-AGR-0001): “APMed” project (Apple and Peach in Mediterranean orchards). The PACA region (Provence-Alpes-Côtes d'Azur) and INRA (Institut National de Recherche Agronomique) founded the PhD grant of A. Rousselin. The GIS-Fruit (Groupement d'Intérêt Scientifique- Fruits) funded the internship grant of A. Sghaier. We would like to thank P.E. Lauri for providing the plant material used in this study and for advice. We would like to thank V. Serra, J.P. Lacroze and F. Bouvery for their technical help. The authors are grateful to A. Sghaier, N. Carles and S. Masson for their contribution to the field measurements.

\section{References}

Agele SO, Ofuya TI, James PO (2006) Effects of watering regimes on aphid infestation and performance of selected varieties of cowpea (Vigna unguiculata L. Walp) in a humid rainforest zone of Nigeria. Crop Prot 25: 7378. doi:10.1016/j.cropro.2005.03.005 Archer TL, Bynum ED, Onken AB, Wendt C.W (1995) Influence of water and nitrogen-fertilizer on biology of the Russian wheat aphid (Homoptera, Aphididae) on wheat. Crop Prot 14: 165-169. doi:10.1016/0261-2194(95)92872K

Ballester C, Jimenez-Bello MA, Castel JR, Intrigliolo DS (2013) Usefulness of thermography for water stress detection in citrus and persimmon trees. Agric For Meteorol 168:120-129.doi:org/10.1016/j.agrformet.2012.08.005 Banfield-Zanin JA, Leather SR (2014) Frequency and intensity of drought stress alters the population size and dynamics of Elatobium abietinum on Sitka spruce. Ann Appl Biol 165: 260-269. doi: 10.1111/aab.12133 Banfield-Zanin JA, Leather SR (2015) Drought intensity and frequency have contrasting effects on development time and survival of the green spruce aphid. Agric Forest Entomol 17: 309-316. doi: 10.1111/afe.12109 
Bethke JA, Redak RA, Schuch UK (1998) Melon aphid performance on chrysanthemum as mediated by cultivar,

389 and differential levels of fertilization and irigation. Entomol Exp Appl 88:41-47. doi:10.1046/j.1570-

$390 \quad 7458.1998 .00344 . x$

391 Bevacqua D, Genard M. Lescourret F (2012) A simple model to predict the probability of a peach (Prunus

392 persicae) tree bud to develop as a long or short shoot as a consequence of winter pruning intensity and previous

393 year growth. PLoS ONE 7: e52185. doi:10.1371/journal.pone.0052185

394 Bolker BM (2008) Ecological Models and Data in R. Princeton University Press, Princeton, NJ.

Brouwer R (1983) Functional equilibrium: sense or nonsense? Neth J Agr Sci 31: 335-348

Burnham, K P, Anderson D R (2004). Multimodel inference: Understanding AIC and BIC in model selection. Socio

Meth Res 33: 261-304. doi:10.1177/0049124104268644

398 Cabrera HM, Argandona VH, Zuniga GE, Corcuera LJ (1995) Effect of infestation by aphids on the water status of

399 barley and insect development. Phytochemistry 40: 1083-1088. doi:10.1016/0031-9422(95)00325-2

400 Chau A, Heinz KM, Davies FT (2005) Influences of fertilization on Aphis gossypii and insecticide usage. J Appl

401 Entomol 129: 89-97. doi:10.1111/j.1439-0418.2005.00943.89-97

402 Constable GA, Rawson HM (1980) Effect of leaf position, expansion and age on photosynthesis, transpiration and

403 water use efficiency of cotton. Aust J Plant Physiol 7: 89-100

404 Czerniewicz P, Leszczynski B, Chrzanowski G, Sempruch C, Sytykiewicz H (2011) Effects of host plant phenolics

405 on spring migration of bird cherry-oat aphid (Rhopalosiphum padi L.). Allelopathy Journal 27: 309-316

406 Dardeau F, Berthier A, Feinard-Duranceau M, Brignolas F, Laurans F, Lieutier F, Sallé A (2015) Tree genotype

407 modulates the effects of water deficit on a plant-manipulating aphid. Forest Ecol Manag 353: 118-125.

408 doi:10.1016/j.foreco.2015.05.037

409 Delorme R, Ayala V, Touton P, Augé D, Vergnet C (1999) Le puceron cendré du pommier (Dysaphis plantaginea):

410 Etude des mécanismes de résistance à divers insecticides. In: ANPP, P.F. (Ed.), Cinquième conférence

411 internationale sur les ravageurs, Montpellier, France, pp. 89-97.

412 FAO (2016) FAOstat Crops production data 2013.

413 Forrest JMS, Dixon AFG (1975) The induction of leaf-roll galls by the apple aphids Dysaphis devecta and D.

414 plantaginea. Ann Appl Biol 81: 281-288. doi:10.1111/j.1744-7348.1975.tb01643.x

415 Foyer CH, Rasool B, Davey JW, Hancock RD (2016) Cross-tolerance to biotic and abiotic stresses in plants: a

416 focus on resistance to aphid infestation. J Exp Bot 67: 2025-2037. doi:10.1093/jxb/erw079 
Girona J, Behboudian MH, Mata M, Del Campo J, Marsal J (2010) Exploring sixreduced irrigation options under

Manage. 98:370-375. doi:10.1016/j.agwat.2010.09.011

Goggin FL (2007) Plant-aphid interactions: molecular and ecological perspectives. Curr Opin Plant Biol 10: 399-

408. doi:10.1016/j.pbi.2007.06.004

Grechi I, Sauge MH, Sauphanor B, Hilgert N, Senoussi R, Lescourret F (2008) How does winter pruning affect peach tree-Myzus persicae interactions? Entomol Exp Appl 128: 369-379. doi:10.1111/j.1570-7458.2008.00720.x

Hullé M, Coeur d'Acier A, Bankhead-Dronnet S, Harrington R (2010) Aphids in the face of global changes. C R

Biol 333: 497-503. doi:10.1016/j.crvi.2010.03.005

Jordan MO, Wendler R, Millard P (2009) The effect of autumn N supply on the architecture of young peach

(Prunus persica L.) trees. Trees-Struct Funct 23: 235-245. doi:10.1007/s00468-008-0271-2

Jordan MO, Vercambre G, Le Bot J, Adamowicz S, Gomez L, Pages L (2011) Autumnal nutrition affects C and N

storage and architecture of young peach trees. Trees-Struct Funct 25: 333-344. doi: 10.1007/s00468-010-0509-7

Jordan MO, Wendler R, Millard P (2012) Autumnal N storage determines the spring growth, N uptake and N

internal cycling of young peach trees. Trees-Struct Funct 26: 393-404. doi:10.1007/s00468-010-0509-7

132

King C, Jacob HS, Berlandier F (2006) The influence of water deficiency on the relationship between canola

(Brassica napus L.), and two aphid species (Hemiptera: Aphididae), Lipaphis erysimi (Kaltenbach) and

Brevicoryne brassicae (L.). Aust J Agr Res 57: 439-445. doi:10.1071/ar05137

Lauri PÉ, Barigah TS, Lopez G, Martinez S, Losciale P, Zibordi M, Manfrini L, Corelli-Grappadelli L, Costes E,

Regnard JL (2016) Genetic variability and phenotypic plasticity of apple morphological responses to soil water

437 restriction in relation with leaf functions and stem xylem conductivity. Trees-Struct Funct 30:1893-1908. doi:10.1007/s00468-016-1408-3

439 Le Roux X, Bariac T, Sinoquet H, Genty B, Piel C, Mariotti A, Girardin C, Richard P (2001) Spatial distribution of 440 leaf water-use efficiency and carbonisotope discrimination within an isolated tree crown. Plant. Cell Environ. 24: 441 1021-1032.

442 Liu BH, Cheng L, Ma FW, Liang D, Zou YJ (2012) Influence of rootstock on drought response in young 'Gale

443 Gala' apple (Malus domestica Borkh.) trees. J Sci Food Agric 92: 2421-2427. doi:10.1002/jsfa.5647

445 (1998) Nitrogen allocation and carbon isotope fractionation in relation to intercepted radiation and position in a 
447 Lu H, Yang P, Xu Y, Luo L, Zhu J, Cui N, Kang L, Cui F (2016). Performances of survival, feeding behavior, and

448 gene expression in aphids reveal their different fitness to host alteration. Sci Rep 6:19344. doi:10.1038/srep19344

449 Mace KC, Mills NJ (2015) Response of walnut aphid populations to increasing foliar nitrogen content. Agr Forest

450 Entomol 17: 277-284. doi:10.1111/afe.12103

451 Marchetti E, Civolani S, Leis M, Chicca M, Tjallingii WF, Pasqualini,E, Baronio P (2009) Tissue location of 452 resistance in apple to the rosy apple aphid established by electrical penetration graphes. Bull insectology 62: 203453208

454 Mewis I, Khan MAM, Glawischnig E, Schreiner M, Ulrichs C (2012) Water stress and aphid feeding differentially 455 influence metabolite composition in Arabidopsis thaliana (L.). PLoS ONE 7: e48661. 456 doi:10.1371/journal.pone.0048661

457 Mody K, Eichenberger D, Dorn S (2009) Stress magnitude matters: different intensities of pulsed water stress 458 produce non-monotonic resistance responses of host plants to insect herbivores. Ecol Entomol 34: 133-143. 459 doi:10.1111/j.1365-2311.2008.01053.x

460 Neilsen GH, Neilsen D (2003) Nutritional requirements of apple. In: Ferree, D.C., Warrington, I.J. (Eds.), Apples:

461 Botany, production and uses. CABI Publ, Wallingford, UK, pp. 267-302.

462 Nesme T, Plénet D, Hucbourg B, Fandos G, Lauri PE (2005). A set of vegetative morphological variables to 463 objectively estimate apple (Malus domestica) tree orchard vigour. Sci Hortic 106: 76-90. doi: 464 10.1016/j.scienta.2005.02.017

465 Nowak H, Komor E (2010) How aphids decide what is good for them: experiments to test aphid feeding behaviour 466 on Tanacetum vulgare (L.) using different nitrogen regimes. Oecologia 163: 973-984. doi:10.1007/s00442-010$467 \quad 1652-y$

468 Paço TA, Ferreira MI, Pacheco CA (2013) Scheduling peach orchard irrigation in water stress conditions: use of 469 relative transpiration and predawn leaf water potential. Fruits 68: 147-158. doi:10.1051/fruits/2013061

470 Pangga IB, Hanan J, Chakraborty S (2012) Climate change impacts on plant canopy architecture: implications for 471 pest and pathogen management. Eur J Plant Pathol 135: 595-610. doi:10.1007/s10658-012-0118-y

472 Price PW (1991) The plant vigor hypothesis and herbivore attack. Oikos 62: 244-251. doi:10.2307/3545270

473 R Core Team (2016) R: A language and environment for statistical computing. R Foundation for Statistical 474 Computing, Vienna, Austria. 
476 affect peach tree-green peach aphid interactions: the key role played by vegetative growth. Agric Forest Entomol

477 18: 367-375. doi:10.1111/afe.12168

478 Ryalls JM, Moore BD, Riegler M, Gherlenda AN, Johnson SN (2014) Amino acid-mediated impacts of elevated

479 carbon dioxide and simulated root herbivory on aphids are neutralized by increased air temperatures. J Exp Bot 66:

480 613-623. doi:10.1093/jxb/eru439

481 Ryan GD, Shukla K, Rasmussen S, Shelp BJ, Newman JA (2014) Phloem phytochemistry and aphid responses to 482 elevated $\mathrm{CO}_{2}$, nitrogen fertilization and endophyte infection. Agric Forest Entomol 16: 273-283. 483 doi:10.1111/afe.12055

484 Satar S, Kersting U, Uygun N (2008) Effect of temperature on population parameters of Aphis gossypii Glover and 485 Myzus persicae (Sulzer) (Homoptera: Aphididae) on pepper. J.Plant Dis Protect 115: 69-74. doi: $486 \quad 10.1007 / \mathrm{BF} 03356241$

487 Sauge MH, Kervella J, Pascal T (1998) Settling behaviour and reproductive potential of the green peach aphid 488 Myzus persicae on peach varieties and a related wild Prunus. Entomol Exp Appl 89: 233-242.

489 Sevanto S (2014) Phloem transport and drought. J Exp Bot 65: 1751-1759. doi:10.1093/jxb/ert467

490 Simon S, Morel K, Durand E, Brevalle G, Girard T, Lauri PÉ (2011) Aphids at crossroads: when branch 491 architecture alters aphid infestation patterns in the apple tree. Trees 26: 273-282. doi:10.1007/s00468-011-0629-8 492 Simpson KLS, Jackson GE, Grace J (2012) The response of aphids to plant water stress - the case of Myzus 493 persicae and Brassica oleracea var. capitata. Entomol Exp Appl 142: 191-202. doi:10.1111/j.1570494 7458.2011.01216.x

495 Stoeckli S, Mody K, Dorn S (2008) Aphis pomi (Hemiptera: Aphididae) population development, shoot 496 characteristics, and antibiosis resistance in different apple genotypes. J Econ Entomol 101: 1341-1348. 497 doi:10.1603/0022-0493(2008)101[1341:APHAPD]2.0.CO;2

498 Tariq M, Wright DJ, Rossiter JT, Staley JT (2012) Aphids in a changing world: testing the plant stress, plant vigour 499 and pulsed stress hypotheses. Agric Forest Entomol 14: 177-185. doi:10.1111/j.1461-9563.2011.00557.x

500 Tausend PC, Meinzer FC, Goldstein G (2000) Control of transpiration in three coffee cultivars: the role of 501 hydraulic and crown architecture. Trees-Struct Funct, 14: 181-190

502 Verdugo JA, Sauge MH, Lacroze JP, Francis F, Ramirez CC (2015) Drought-stress and plant resistance affect 503 herbivore performance and proteome: the case of the green peach aphid Myzus persicae (Hemiptera: Aphididae).

504 Physiol Entomol 40: 265-276. doi:10.1111/phen.12111 
505 Wheat D (1980) Sylleptic branching in Myrsine floridana (Myrsinaceae). Am J Bot 67(4), 490-499. 506 doi: $10.2307 / 2442288$

507 Zehnder CB, Hunter MD (2009) More is not necessarily better: the impact of limiting and excessive nutrients on 508 herbivore population growth rates. Ecol Entomol 34: 535-543. doi:10.1111/j.1365-2311.2009.01101.x 509 
511 Fig. 1 Absolute values of midday leaf water potential of on apple trees (sample size indicated within the figure for

512 each date), subject to four treatments, combining two levels of water supply (W+ and W-) and two tree genotypes

513 (DAG, drought avoidance genotype and GCG, growth cessation genotype).

514 Each panel corresponds to a date expressed in days after infestation (DAI), and to a total number of $\mathrm{n}$ plants.

515 Different letters indicate significant differences between treatment combinations (Kruskal-Wallis test and Tukey

516 multiple comparisons, performed at each date). No significant differences were observed on DAI =1, 9 and 49 .

517 Fig. 2 Characterisation of leaf functioning of 17 apple trees on 30 DAI (days after infestation) according to the

518 different treatments, combining two tree genotypes: GCG (Growth cessation genotype) and DAG (Drought

519 Avoidance Genotype) and two levels of water supply: W+ and W-. (a) Leaf stomatal conductance, (b) transpiration

520 rate, (c) photosynthetic rate, (d) temperature. Different letters indicate significant differences between treatment

521 combinations (Kruskal-Wallis test and Tukey multiple comparisons).

522 Fig. 3 Vegetative growth dynamics at both shoot (a) and tree (b) scales as an increase of leaves number from 2 to

52364 days after infestation (DAI). Each point represents the mean value for a treatment combination: water supply

524 (W+ and W-) and tree genotype (DAG: Drought Avoidance Genotype and GCG: Growth Cessation Genotype).

525 Bars stand for standard deviation.

526 Fig. 4 Relationship between the number of proleptic shoots per tree and final vegetative growth variables in 527 increase in number of leaves at tree (FTVG) and shoot (FSVG) scales. (a) FTVG as a function of FSVG, the 528 regression lines result from the selected best model (based on AICc, $\mathrm{R}^{2}{ }_{\text {adj }}=0.74$ ) including FSVG, W (water treatment), V (tree genotype) and the interaction FSVG $\times$ V. (b) FTVG as a function of the number of proleptic

530 shoots per tree: the regression lines result from the selected best model $\left(\mathrm{R}^{2}{ }_{\mathrm{adj}}=0.68\right)$ including the number of

531 proleptic shoots, $\mathrm{W}, \mathrm{V}$ and the interaction the number of proleptic shoots and genotype. (c) FSVG as a function of 532 the number of proleptic shoots: the regression lines result from the selected best model $\left(\mathrm{R}^{2}{ }_{\text {adj }}=0.34\right)$ including $\mathrm{W}$

533 and V. Notice that FTVG and FSVG have been log transformed to fulfil the conditions required for statistical 534 analysis

535 Fig. 5 Aphid abundance temporal dynamics (mean \pm standard deviation) for each treatment combination at (a) the infested shoot scale and (b) the tree scale for the different dates (in days after infestation: DAI).

537 Fig. 6 Relationship between final shoot vegetative growth (FSVG) and shoot aphid index. Each point represents 538 the value of the apical shoot of a tree. The regression lines result from the selected best model (based on AICc, $\left.539 \mathrm{R}_{\text {adj }}{ }^{2}=0.52\right)$ including FSVG, water treatment $\mathrm{W}$, tree genotype $\mathrm{V}$ and the interaction term $(\mathrm{W} \times \mathrm{V})$ as explanatory

540 variables and factors. Notice that FSVG has been log transformed to fulfil the conditions required for statistical 541 analysis.

542 Fig. 7 Relationship between tree aphid index and final tree vegetative growth (FTVG). Each point represents the 543 value of a single tree. The regression lines result from the selected best model (based on AICc, $\mathrm{R}^{2}{ }_{\text {adj }}=0.42$ ) 544 including FTVG, water treatment W and the interaction term FTVG $\times \mathrm{H}$, as explanatory variable and factor. Notice 545 that FTVG has been log transformed to fulfil the conditions required for statistical analysis. 
548

549

550

551

552

553

554

555

556

557

558

559

560

561

562

563

564

565

566

567

568

569

570

571

572

573

574

575

576

577

Figure 1: 2 columns fitting image, original size $(\mathrm{w} / \mathrm{l}) 16 * 21 \mathrm{~cm}$ in a separate eps file

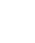

3
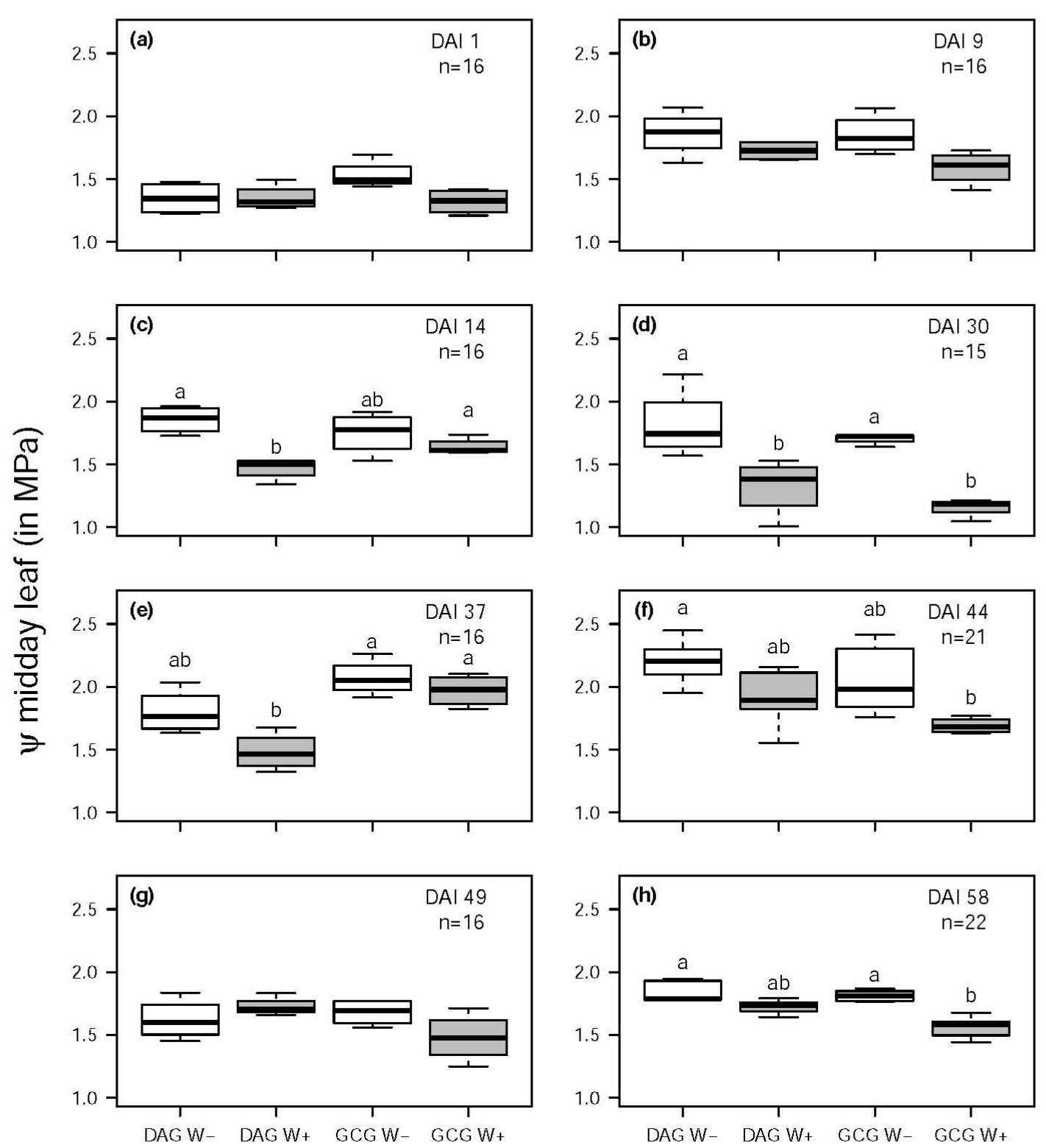

Treatment combination 


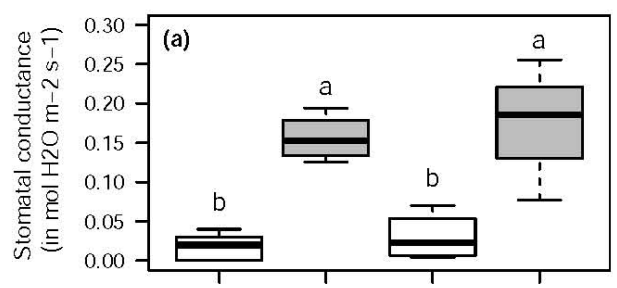

595

596

597

598
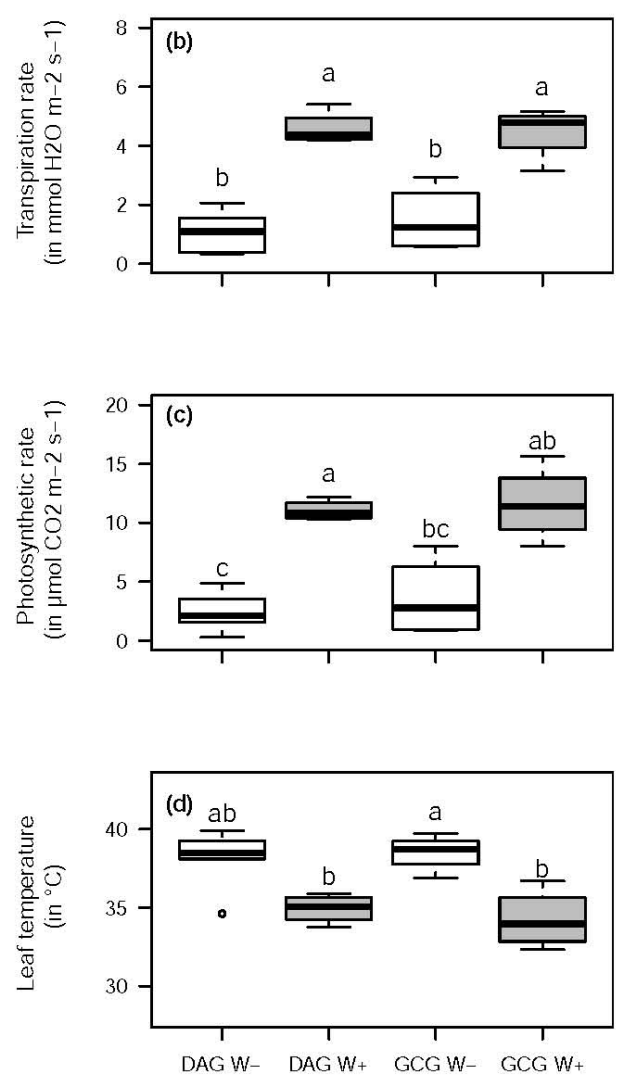

Treatment combination 
599 Figure 3: 2 columns fitting image, original size (w/l) $14 * 14.5 \mathrm{~cm}$ in a separate eps file
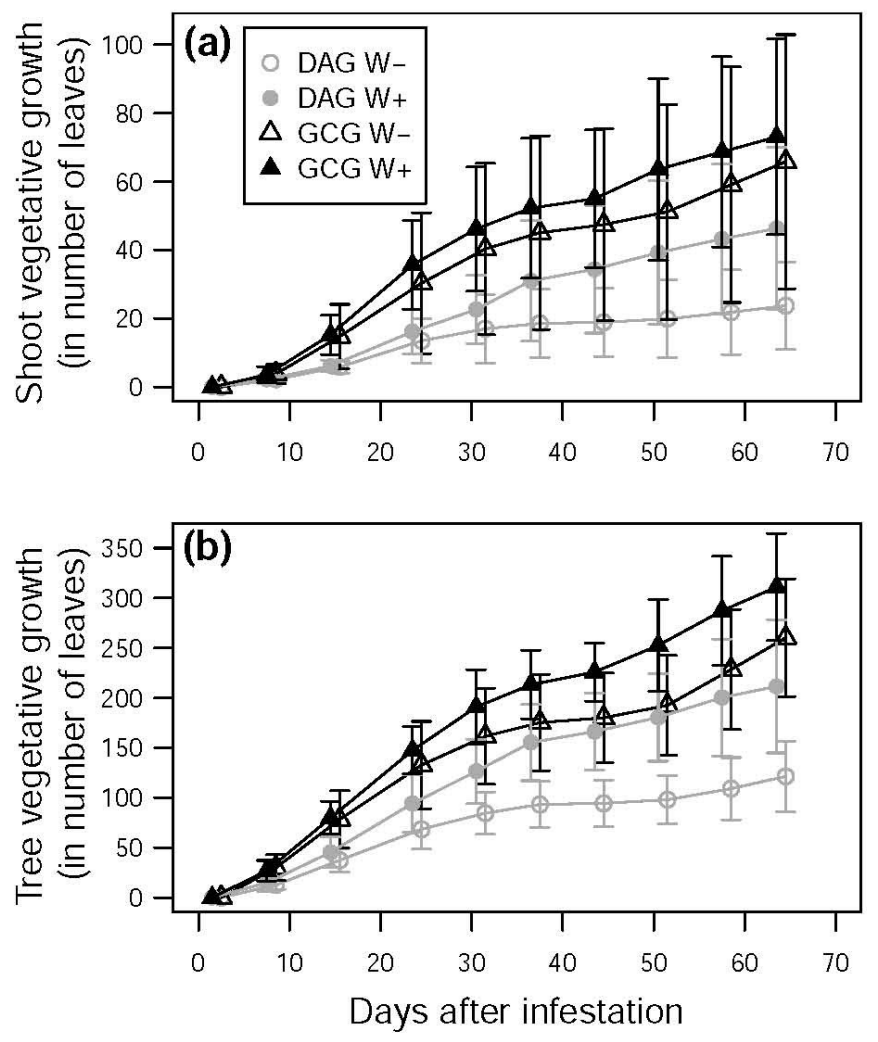

600

601 
Figure 4: 2 columns fitting image, original size $(w / 1) 17.5 * 21 \mathrm{~cm}$ in a separate eps file 603
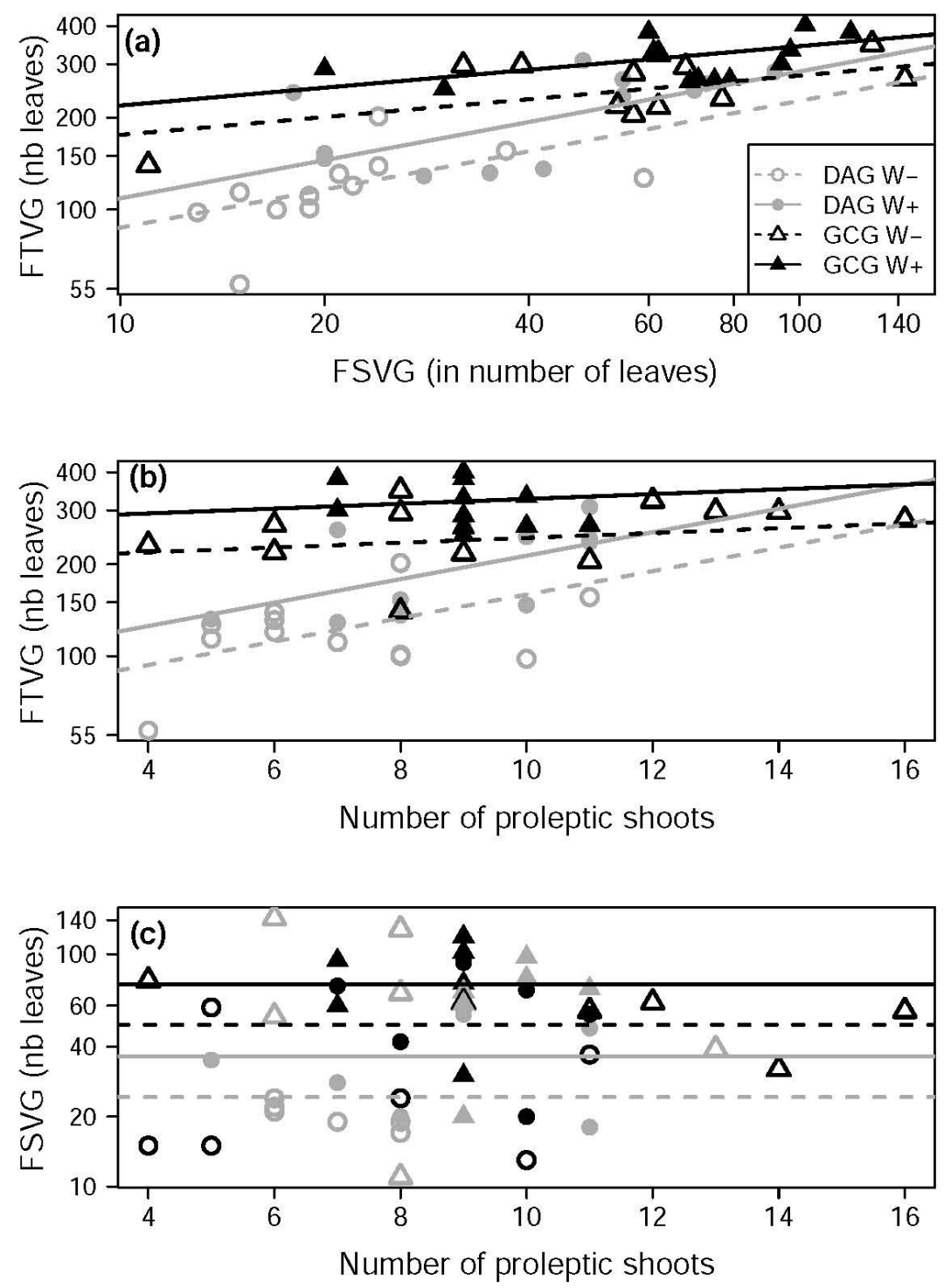

604

605 
607 Figure 5: 2 columns fitting image, original size (w/l) $14 * 14.5 \mathrm{~cm}$ in a separate eps file 608
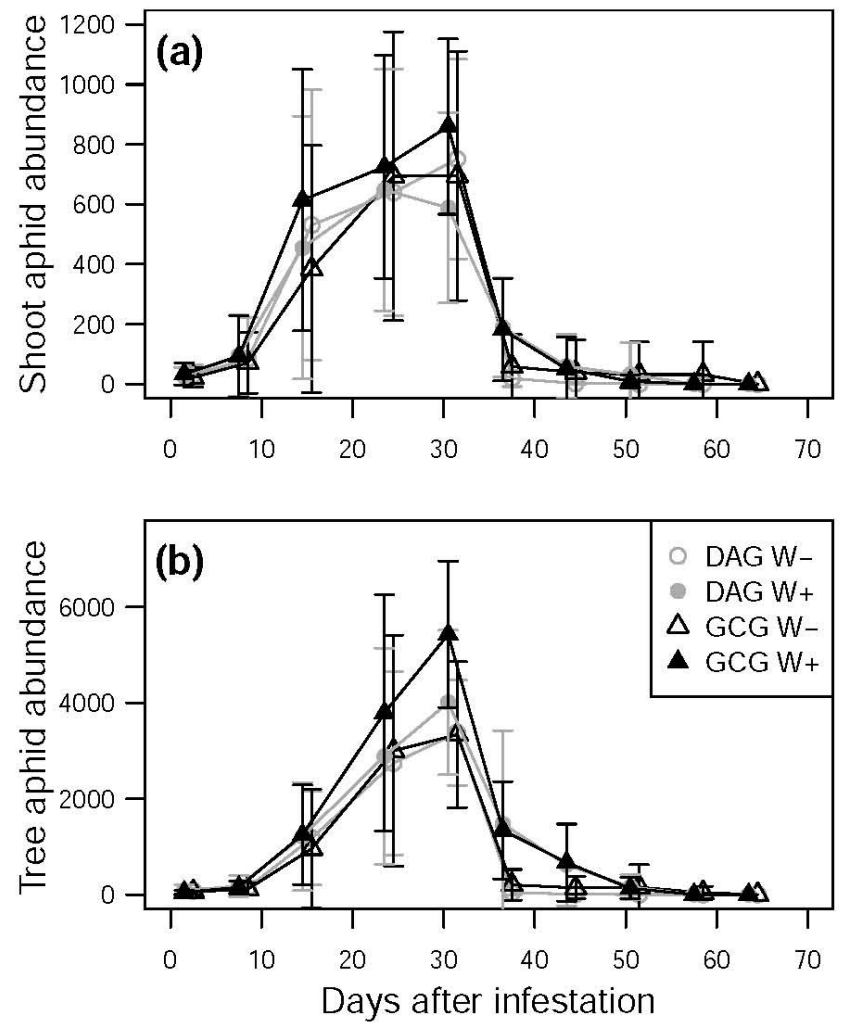
610 Figure 6: 1 column fitting image, original size (w/l) $12 * 12 \mathrm{~cm}$ in a separate eps file

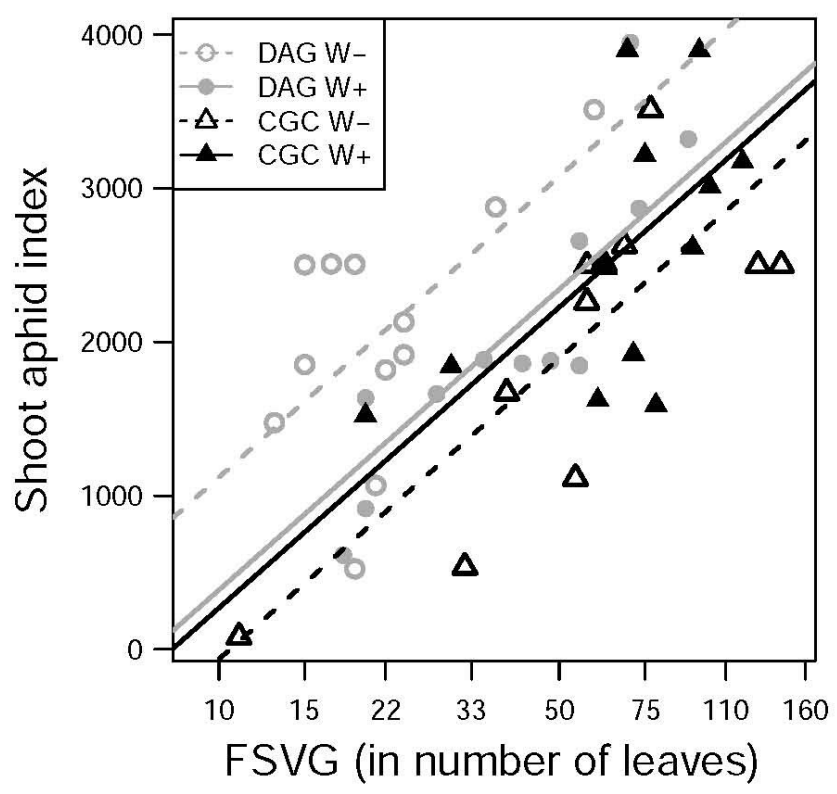

611

612 
613 Figure 7: 1 column fitting image, original size (w/l) $12 * 12 \mathrm{~cm}$ in a separate eps file 614

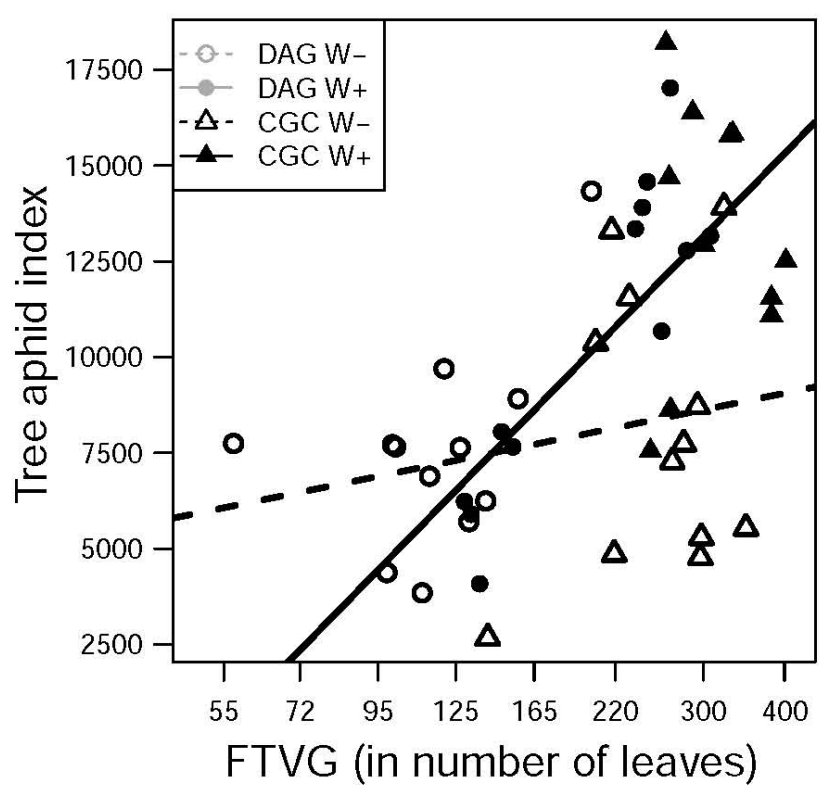

615 